\title{
Influence of Tetrahydrofuran (THF) in the Synthesis of Zeolite ZK-5
}

L. J. Garces ${ }^{1 \#, *}$, B. Hincapie ${ }^{1 \#}$, X. Shen ${ }^{1}$, V. D. Makwana ${ }^{2}$, D. R. Corbin ${ }^{3}$, A. $\operatorname{Sacco}^{4}$ S. L. Suib $^{1,2,5, *}$

1. Institute of Materials Science, University of Connecticut, Storrs, Connecticut 06269

2. Department of Chemistry, U-60, University of Connecticut, Storrs, Connecticut 062693060

3. Central Research and Development, DuPont Company, Inc., Experimental Station, P.O. Box 80262, Wilmington, Delaware, 19880-0262 USA

4. Department of Chemical Engineering, Northeastern University, 342 Snell Engineering, Boston, MA, 02115

5. Department of Chemical Engineering, University of Connecticut, Storrs, CT, 06269.

\# Currently Laboratorio de Catálisis Industrial, Instituto de Química, Facultad de Ciencias Exactas y Naturales, Universidad de Antioquia UdeA, Calle 70 No 52-21, Medellín, Colombia.

* Author to whom correspondence should be sent, $\underline{\text { Steven.Suib@uconn.edu }}$ 


\begin{abstract}
ZK-5 (KFI) molecular sieve was synthesized in the $\mathrm{K}_{2} \mathrm{O}: \mathrm{SrO}: \mathrm{Al}_{2} \mathrm{O}_{3}: \mathrm{SiO}_{2}: 160 \mathrm{H}_{2} \mathrm{O}$ : THF system using conventional hydrothermal heating. Effect of tetrahydrofuran (THF) was investigated. Products were characterized by XRD, TGA, FESEM, EDX and TPDMS. THF influences the crystallinity and crystal size of ZK-5. The molar ratio of $\mathrm{THF} / \mathrm{Al}_{2} \mathrm{O}_{3}$ from 0.4 to 1.0 gives the best results in terms of crystallinity (measured by XRD) and purity for the prepared ZK-5. Crystal size of ZK-5 zeolite is reduced by the presence of THF.
\end{abstract}

Keywords: Molecular sieves, Tetrahydrofuran (THF), ZK-5. 


\section{Introduction}

The use of amines as templates in the synthesis of zeolites is well known and documented [1-3]. Organic compounds containing no nitrogen are rarely used as templates. The first detailed investigation of the use of THF in the synthesis of MOR, FER, MFI and MTN-type zeolites was reported by Qian et.al [4]. In that case THF was used as a template for the synthesis of high-silica zeolites due to its strong affinity with the framework siliceous [4]. Y.C. Long, et. al reported the use of THF in the synthesis of FER type zeolite with and without glycerol as organic additive[5, 6].

Zeolite ZK-5 (KFI) is a low silica zeolite with a high free pore volume of 0.305 $\mathrm{cm}^{3} / \mathrm{g}$ [7]. Pore topology of this zeolite consists of two types of cages, alpha and gammacages [8]. Synthesis of methylamines has been tried with acid ZK-5 as a catalyst. [9-12]. According to previous work, the structure of ZK-5 provides a promising medium for hydrogen storage [13]. It has been indicated that it is difficult to produce pure ZK-5 in the Sr, K system [13], as opposed to the Cs, K-ZK-5 system [14], and also that few literature for this system exists [13]. In this work we report the crystallization behavior of zeolite ZK-5 under hydrothermal conditions and with THF in the reactant system $\mathrm{K}_{2} \mathrm{O}$ : SrO: $\mathrm{Al}_{2} \mathrm{O}_{3}: \mathrm{SiO}_{2}: 160 \mathrm{H}_{2} \mathrm{O}$ : THF. Effects of a non-nitrogen organic additive like THF on particle size, purity and crystallinity have been investigated. Standard synthesis temperature and time for hydrothermal synthesis of $\mathrm{ZK}-5$ are $150^{\circ} \mathrm{C}$ and $144 \mathrm{~h}$ with a batch composition of $2.3 \mathrm{~K}_{2} \mathrm{O}: 0.1 \mathrm{SrO}: \mathrm{Al}_{2} \mathrm{O}_{3}: 10 \mathrm{SiO}_{2}: 160 \mathrm{H}_{2} \mathrm{O}$ [15]. The aim of this work was to synthesize K, Sr-ZK-5 with improved crystallinity, and purity by using tetrahydrofuran, a cheaper reagent than $\mathrm{DABCO}$ or 18 -crown-6 ether, both used previously in the synthesis of ZK-5 $[16,17]$. 


\section{Experimental}

Strontium hydroxide octahydrate was dissolved in double de-ionized water (DDW). Colloidal silica Ludox (R) was added to this solution. The solution was stirred until a gel was formed. Aluminum metal was dissolved in an aqueous solution of potassium hydroxide. This second solution was added simultaneously with THF to the gel that was first prepared. Water content was adjusted to this final mixture. Final solution was stirred at room temperature for 30 minutes. The gel was charged into a Teflon (R) lined stainless steel autoclave for conventional hydrothermal synthesis. Batch composition of crystallization mixtures is given in Tables 1 to 3 . Temperature was kept at $150^{\circ} \mathrm{C}$.

Solid products were recovered by centrifugation and washed with de-ionized water until $\mathrm{pH}$ of washing water was neutral. Products were dried at $100^{\circ} \mathrm{C}$ overnight. Products were characterized by XRD on a Scintag XDS-200 powder diffractometer on finely powdered samples using $\mathrm{Cu}-\mathrm{K} \alpha$ radiation. The crystal size reported is the average of the values obtained by applying Scherrer's equation to lines $2 \theta: 9.44,20.12,21.22$, 29.41, and 31.70. The instrumental line broadening was measured using a LaB6 standard. Crystallinity of samples was calculated by XRD using the method reported by Szostak [18]. The sample with the most intense ZK-5 diffraction peaks was selected as a standard (Run 4) and 100\% crystallinity was assigned to it. The crystallinity of the others samples was relative to this standard. The sum of the intensities of the peaks at $2 \theta 9.44,20.12$, $21.22,29.41$ and 31.70 [13] for each sample was divided by the sum of the intensity of the same peaks for the standard and multiplied by 100 . 
Morphology was determined on a Zeiss DSM 982 Gemini field emission scanning electron microscope (FESEM) with a Schottky emitter at an accelerating voltage of $2 \mathrm{kV}$ with a beam current of about $1 \mu \mathrm{A}$. An ECON IV energy dispersive X-ray (EDX) analyzer model 9800 was used for EDX studies. An average of three analyses was done to calculate average concentrations and chemical compositions.

Thermogravimetric analysis (TGA) was done on a DuPont 951 Thermogravimetric Analyzer. Temperature programmed desorption-mass spectrometry (TPD-MS) was used to determine THF. Approximately $20 \mathrm{mg}$ of sample 6 (See Table 1 for description of sample) was packed in a quartz tube and loaded to a tubular furnace equipped with an Omega temperature controller. Samples were purged with helium for 4 $\mathrm{h}$ at room temperature followed by heating to $700^{\circ} \mathrm{C}$ at $15^{\circ} \mathrm{C} / \mathrm{min}$. Helium carrier gas at the exhaust was analyzed with a MKS-UTI PPT quadrupole residual gas analyzer. Evolution of water $(\mathrm{m} / \mathrm{z} 18)$, oxygen $(\mathrm{m} / \mathrm{z} 32)$, carbon dioxide $(\mathrm{m} / \mathrm{z} 44)$, and tetrahydrofuran $(\mathrm{m} / \mathrm{z} 42, \mathrm{~m} / \mathrm{z} 72)$ were monitored.

\section{Results}

XRD patterns of samples prepared with different $T H F / \mathrm{Al}_{2} \mathrm{O}_{3}$ ratio, described in Table 1, are shown in Figure 1. XRD results show that the position of the peaks of samples prepared with different $\mathrm{THF} / \mathrm{Al}_{2} \mathrm{O}_{3}$ ratio (Fig. $1 \mathrm{~b}$ to $1 \mathrm{~d}$ ) is similar to that for $\mathrm{ZK}$ 5 (Fig. 1a) with a difference only in the intensities [16, 19]. The molar ratio of $\mathrm{THF} / \mathrm{Al}_{2} \mathrm{O}_{3}$ from 0 to 0.5 was used in the case of samples shown in Figure 1a to $1 \mathrm{~d}$. An increase in crystallinity of ZK-5 was observed when a $T H F / \mathrm{Al}_{2} \mathrm{O}_{3}$ of 0.5 was used. Increasing the $\mathrm{THF} / \mathrm{Al}_{2} \mathrm{O}_{3}$ ratio from 2 to 3 (Fig. $1 \mathrm{f}$ and Fig. $1 \mathrm{~g}$ ) produced ERI (ERI is the three letter code of the International Zeolite Association for zeolite with the erionite 
framework) impurities in the $\mathrm{X}$-ray pattern $[13,20]$. $\mathrm{THF} / \mathrm{Al}_{2} \mathrm{O}_{3}$ ratio of 1 (Fig.1e) shows $\mathrm{X}$-ray pattern that corresponds to $\mathrm{ZK}-5$. These results suggest that when the $\mathrm{THF} / \mathrm{Al}_{2} \mathrm{O}_{3}$ ratio is kept between 0.4 and 1 the best results in terms of crystallinity of ZK-5 are obtained. Further increase in THF/ $\mathrm{Al}_{2} \mathrm{O}_{3}$ favors the formation of ERI type zeolite. The crystal size of ZK-5 measured by XRD decreased with the use of THF. From SEM micrographs (Fig 2), the particle size of ZK-5 prepared with THF is similar to that of ZK5 prepared without THF, but the particles of ZK-5 prepared with THF have a less smooth surface.

Effects of changing the Si/Al ratio by decreasing aluminum in the initial gel can be seen in Tables 2 and 3. X-ray patterns can be seen in Figure 3. Table 2 and Fig. 3a to $3 \mathrm{~d}$ show the effect of increasing the Si/Al ratio in the synthesis of ZK-5 without THF and Table 3 and Fig. $3 \mathrm{e}$ to $3 \mathrm{~h}$ show the change in $\mathrm{Si} / \mathrm{Al}$ ratio using a constant ratio of THF/ $/ \mathrm{Al}_{2} \mathrm{O}_{3}$ of 0.5 . From Fig. $3 \mathrm{~b}(\mathrm{Si} / \mathrm{Al}=2.7)$ the position of peaks is similar to those of the prepared ZK-5 (Fig. 3a). When the Si/Al ratio is increased to 2.80 by decreasing the aluminum content in the initial batch composition by 20 mol\% (Fig. 3c) the crystalline structure of ZK-5 is preserved and an ERI co-crystallization phase is present in the X-ray pattern. A further increase in $\mathrm{Si} / \mathrm{Al}$ ratio to 3.6 by decreasing the aluminum content of the initial reacting gel by a $30 \mathrm{~mol} \%$ leads to an amorphous material (Fig. 3d).

A similar trend is shown in Fig. $3 \mathrm{e}$ to $3 \mathrm{~h}$ when $\mathrm{Si} / \mathrm{Al}$ is changed from 2.7 to 3.5 keeping a constant $\mathrm{THF} / \mathrm{Al}_{2} \mathrm{O}_{3}$ ratio of 0.5 . A decrease of $30 \mathrm{~mol} \%$ in the aluminum content of the initial reacting gel with $\mathrm{THF} / \mathrm{Al}_{2} \mathrm{O}_{3}$ ratio equal to zero and 0.5 resulted in both cases in amorphous material as shown in Fig. 3d and $3 \mathrm{~h}$. 
The addition of THF to the reacting gel with increased $\mathrm{Si} / \mathrm{Al}$ ratio favors the formation of a higher ERI type zeolite to ZK-5 ratio. Comparing experiments from Tables 2 and 3, the addition of THF in a molar ratio of $\mathrm{THF} / \mathrm{Al}_{2} \mathrm{O}_{3}$ of 0.5 to a reacting gel of $\mathrm{ZK}-5$ whose $\mathrm{Si} / \mathrm{Al}$ ratio has been increased up to $10 \mathrm{~mol} \%$ by a decrease in the aluminum content of the initial reacting gel, improves the crystallinity of the product. Further increases in this $\mathrm{Si} / \mathrm{Al}$ ratio (See runs 12 and 13. Table 3) favor the production of ERI type zeolite in the first case, and amorphous material in the second case. Fig. 4 shows the SEM micrographs of ZK-5 prepared with different Si/Al ratio with and without THF. The particle size of ZK-5 does not seem to be greatly affected by the addition of THF, but the surfaces of the particles seem to have more defects than the ZK-5 prepared without THF.

TGA and TPD-MS analyses for sample labeled 6 with a THF/ $/ \mathrm{Al}_{2} \mathrm{O}_{3}$ molar ratio of 2 (see Table 1 for description of sample) can be seen in Figs. 5 and 6 where evidence of THF is observed. The weight loss at around $100{ }^{\circ} \mathrm{C}$ corresponds to the loss of physisorbed water in the sample [21]. A weight loss peak due to THF escaping from ZK5 occurs at $250-400^{\circ} \mathrm{C}$ as shown in TG analysis (Fig 5). TPD-MS results for ZK-5 with a molar ratio $\mathrm{THF} / \mathrm{Al}_{2} \mathrm{O}_{3}$ of 2 (entry 6 Table 1 ) is in agreement with this result. Evolution of THF (m/z 42 and 41) from ZK-5 is shown in Fig 6. Mass peaks at m/z 42 and 41 were selected because they are the most abundant fragments in the THF mass spectrum [22]. Evolution of $\mathrm{THF}$ starts at $200^{\circ} \mathrm{C}$ reaching a maximum at around $300^{\circ} \mathrm{C}$ and is totally gone at $400^{\circ} \mathrm{C}$. The $\mathrm{m} / \mathrm{z}$ value is mainly 42 , which indicated that $\mathrm{THF}$ comes off the sample mostly as THF not as a decomposition product. 


\section{Discussion}

THF, $\left(\mathrm{CH}_{2}\right)_{4} \mathrm{O}$, plays and important role in the crystallization of $\mathrm{ZK}-5$. THF is polar cyclic ether; the oxygen has two lone electron pairs, which can form hydrogen bonds with HO-groups from water or silanol, and complexes with cations. At low temperature THF forms hydrogen bonds with water [23] as the temperature increases, the association between THF and water decreases, there is more THF available to interact with other species [24]. In the reacting gel the oxygen of THF could interact with $\mathrm{K}^{+}$, $\mathrm{Sr}^{2+}, \mathrm{Al}^{3+}$, water, and $\mathrm{Si}-\mathrm{OH}$. Atwood, et. al [25] were able to crystallize a complex between THF and aluminum chloride, they reported that there is a strong interaction between the free electrons of THF's oxygen and the positive charges of aluminum.

ZK-5 with the highest crystallinity and purity among the synthesized products was obtained in the range of $\mathrm{THF} / \mathrm{Al}_{2} \mathrm{O}_{3}$ from 0.4 to 1 . At a higher molar ratio of $\mathrm{THF} / \mathrm{Al}_{2} \mathrm{O}_{3}$, ERI zeolite co-crystallized with $\mathrm{ZK}-5$. Increasing the $\mathrm{Si} / \mathrm{Al}$ ratio of the reacting gel, without THF, ERI type zeolite co-crystallized with ZK-5. Amorphous material was formed when the $\mathrm{Si} / \mathrm{Al}$ ratio was further increased. These results are consistent with those reported, for the synthesis of ZK-5 under similar conditions, by Russell, et.al [13]. Zeolites are metastable phases and ERI type zeolite is in the crystallization field of ZK-5.

The reacting gel with a molar ratio $\mathrm{SiO}_{2} / \mathrm{Al}_{2} \mathrm{O}_{3}$ of 10 produced $\mathrm{ZK}-5$ cocrystallized with ERI type zeolite when the ratio of $\mathrm{THF} / \mathrm{Al}_{2} \mathrm{O}_{3}$ increased from 1 to 3 . Apparently, the effect of increasing the $\mathrm{THF} / \mathrm{Al}_{2} \mathrm{O}_{3}$ ratio has the same effect as increasing the $\mathrm{SiO}_{2} / \mathrm{Al}_{2} \mathrm{O}_{3}$ in absence of THF. This may indicate that THF was interacting with the 
species in the starting gel, increasing the effective $\mathrm{SiO}_{2} / \mathrm{Al}_{2} \mathrm{O}_{3}$ molar ratio. THF could interact with $\mathrm{Al}^{3+}$ forming complexes [25].

When the molar ratio $\mathrm{THF} / \mathrm{Al}_{2} \mathrm{O}_{3}$ was kept in the range 0.4 to 1.0 , and the $\mathrm{SiO}_{2} / \mathrm{Al}_{2} \mathrm{O}_{3}$ was 10 , the crystallinity of $\mathrm{ZK}-5$ was improved (85 to $100 \%$ ) compared to the material synthesized without THF. Apparently, THF contributes to the transformation of amorphous gel to crystalline zeolite. The mechanism of such transformation is very complex due to the heterogeneity of the mixture and it is more difficult to study than the crystallization from clear suspensions [1].

Results of thermogravimetric analysis for the zeolites synthesized with THF (results not shown here) were similar to those presented in figure 5. A weight loss at around $100{ }^{\circ} \mathrm{C}$ related to the loss of physisorbed water, and a weight loss at temperature higher than $200^{\circ} \mathrm{C}$, which corresponds to the loss of THF was detected. The temperature at which THF was release from the solid was higher than its boiling point maybe due to a) strong interaction between the organic molecule and the inorganic framework [26-28], b) the process of adsorption/desorption in the pores of a zeolite could be studied as capillary condensation, in this process the boiling point of liquids is higher than the boiling point in free state at normal pressure [28], and c) the aperture of the channel is a eight membered ring that difficult the desorption process [16].

Adsorption of THF after ZK-5 crystal formation should be very difficult. The size of the THF molecule is $0.52 \times 0.52 \times 0.49 \mathrm{~nm}$ [4], larger than the pore size of ZK-5 $(0.39 \mathrm{~nm})$ and ERI $(0.36 \mathrm{x} 0.51 \mathrm{~nm})$ [29]. The aluminosilicate framework must grow around the THF molecule [15]. 
The crystal size of ZK-5 synthesized with THF, calculated using Scherrer's equation from the XRD pattern, was smaller (Run 4, $66 \mathrm{~nm}$ ) compared to ZK-5 synthesized under similar conditions but without THF (Run 1, $87 \mathrm{~nm}$ ). These samples have similar particle size from SEM micrographs (Figures $2 \mathrm{a}$ and $2 \mathrm{~d}$ ). The surface of the cubic particles, typical of ZK-5, becomes less smooth when the content of THF in the reacting gel was increased (Figure 2).

The effect in size and shape of zeolites synthesized in presence of organic molecules that can form complexes with aluminum was studied by T. Ban et. al. [30]. In some cases the crystal size of one type of zeolite increased and the crystal surface was smooth, with other organic ligands the opposite effect was observed.

M. W. Anderson et. al [31] studied crystal growth of zeolites and according to them, it is a layer growth process. The density of defect sites increases when the nucleation rate increases; they also mentioned that the structure directing agents lock into the growing surface and help attaching the new layer.

The surface roughness of the crystals increased when the $\mathrm{THF} / \mathrm{Al}_{2} \mathrm{O}_{3}$ ratio increased. The presence of THF in the gel could increase the nucleation rate, and reduce the rate of crystal growth, decreasing the crystal size of the zeolite. THF in excess increases surface roughness maybe because the polar part of THF interacts with one layer of the framework and the apolar (-CH-) part of the THF attached to the surface of a growing crystal may repel a new layer, reducing crystal size and increasing density of defects. 


\section{Conclusions}

THF influences the crystallinity and crystal size of ZK-5. The molar ratio of $\mathrm{THF} / \mathrm{Al}_{2} \mathrm{O}_{3}$ from 0.4 to 1.0 gives the best result in terms of crystallinity and purity for the prepared ZK-5. Crystal size of ZK-5 zeolite is reduced by the presence of THF. As the $\mathrm{Si} / \mathrm{Al}$ ratio increases with a decrease in aluminum content in the initial batch composition, the ERI co-crystallization phase appeared along with ZK-5 zeolite.

\section{Acknowledgements}

We acknowledge support from the Geosciences and Bioscience Division, Office of Basic Energy Sciences, Office of Science, U.S. Department of Energy and NASA/CAMMP.

L.J. Garces and B. Hincapie acknowledge support from CODI, Universidad de Antioquia during the manuscript revision process. 


\section{References}

1. M. E. Davis, R. F. Lobo, Chem Mater. 4 (1992) 756.

2. R. F. Lobo, S. I. Zones, M. E. Davis, J. Inclusion Phenom. Mol. Recognit. Chem. 1 (1991) 47.

3. G. -Q. Guo, Y.-C. Long, Advances in Chemical Industry. 19 (2000) 16.

4. B. Qian, G. Guo, X. Wang, Y. Zeng, Y. Sun, Y. Long, Phys. Chem. Chem. Phys. 3 (2001) 4164.

5. G. Q. Guo, Y.J. Sun, Y.C. Long, Studies in Surface Science and Catalysis 135 (2001) (Zeolites and Mesoporous Materials at the Dawn of the 21 st Century) 527.

6. X.-W. Cheng, J.Wang, J. Guo, H.Y. He, Y.. C. Long. Micropor. Mesopor. Mater. 119 (2009) 60-67.

7. J. Jänchen, J. H. M. C. van Wolput, W. J. M. van Well, H. Stach, Thermochimica Acta. $379(2001) 213$.

8. W.J.M. Van Well, J. Jaenchen, J.W. De Haan, R.A. Van Santen, Journal of Physical Chemistry B 103 (1999) 1841.

9. S. Schwarz, D.R. Corbin, G.C. Sonnichsen, Microporous and Mesoporous Materials. 22 (1998) 409.

10. D.R. Corbin, S. Schwarz, U.S. Patent No. 5344989 (1994).

11. L. Abrams, D.R.Corbin, R.D. Shannon, U.S. Patent No. 4814503 (1989).

12. R. D. Shannon, M. Keane, L. Abrams, R. H. Staley, T. E. Gier, G. C. Sonnichsen, Journal of Catalysis. 115 (1989) 79.

13. P.C. Russell, S.L. Stuhler, A.L. Kouli, J. Warzywoda, A. Sacco, Jr, Studies in Surface Science and Catalysis. 135 (2001) 295. 
14. H.E. Robson, U.S. Patent No. 3720753 (1973).

15. J.P. Verduijn, U.S. Patent No. 4994249 (1991).

16. T.Chatelain, J. Patarin, R. Farré, O. Pétigny, P. Schulz. Zeolites. 17 (1996) 328.

17. G.T. Kerr. Inorganic Chemistry. 5 (1966) 1539.

18. R. Szostak, Molecular Sieves Principles of Synthesis and Identification, 2nd edition, Thomson Science, London, 1998.

19. J.F. Yang, R. Krishna, J.M. Li, J.P. Li. Microporous and Mesoporous Materials 184 (2014) 21-27.

20. M.M.J. Treacy, J.B. Higgins. Collection of Simulated XRD Powder Patterns for Zeolites. 4 ed. Elsevier, Amsterdam, 2001.

21. G. Pál-Borbéley, in: H.G. Karge, J. Weitkamp (Eds.), Characterization II. Molecular Sieves. Sciencie and Technology, Springer-Verlag, Berlin, 2007, pp. 67-102.

22. M. Dampc, E. Szymanska, B. Mielewska, M. Zubek. J. Phys. B: Atomic, Molecular and Optical Phys. 44, 5(2011) 55206.

23. Sh.I. Mamatkulov, O.B. Ismailova, A.A. Saidov, P.K. Khabibullaev Doklady Physical Chemistry 430 (2010) 5-9.

24. R.P.W Scott. J. Liq. Chrom and Rel. Technol. 23 (2000) 3083-3093

25. N.C. Means, C.M. Means, S.G. Bott, J. L. Atwood. Inorg. Chem 26 (1987) 14661468

26. Y.C. Long, H.W.Jiang, H. Zong, Langmuir. 13 (1997) 4094.

27. B. Qian, H.W.Jiang, Y.J. Sun, Y.C. Long, Langmuir. 17 (2001) 1119.

28. H. Yang, Z.H. Ping, G.X. Niu, H.W. Jiang, Y.C. Long, Langmuir. 15 (1999) 5382. 
29. W.M. Meier, D.H. Olson, Ch. Baerlocher, Atlas of Zeolite Structure Types, 4th edition, Elsevier, London, 1996.

30. T. Ban, M. Takamura, M. Morikawa, Y. Ohya. Materials Chemistry and Physics 137 (2013) 1067-1072.

31. M.W. Anderson, J. R. Agger, N. Hanif, O. Terasaki. Microporous and Mesoporous Materials 48 (2001) 1-9. 
Table 1

Influence of $\mathrm{THF} / \mathrm{Al}_{2} \mathrm{O}_{3}$ ratio on the crystallization of $\mathrm{ZK}-5$.

\begin{tabular}{cccc}
\hline Run & THF (x) & $\begin{array}{c}\text { Average Crystal Size } \\
\text { ZK-5 (nm) }\end{array}$ & \% Crystallinity \\
No. & \multicolumn{3}{c}{ (n) } \\
\hline 1 & 0 & 42 & 86 \\
2 & 0.2 & 72 & 52 \\
3 & 0.4 & 66 & 85 \\
4 & 0.5 & 65 & 100 \\
5 & 1 & 43 & 89 \\
6 & 2 & 53 & 57 \\
7 & 3 & & 36 \\
\hline
\end{tabular}

Conventional hydrothermal synthesis. Time $144 \mathrm{~h}, \mathrm{Temp}=150^{\circ} \mathrm{C}$. Batch Composition $2.3 \mathrm{~K}_{2} \mathrm{O}: 0.1 \mathrm{SrO}: \mathrm{Al}_{2} \mathrm{O}_{3}: 10 \mathrm{SiO}_{2}: 160 \mathrm{H}_{2} \mathrm{O}: \mathrm{x}$ THF 
Table 2

Influence of different $\mathrm{Si} / \mathrm{Al}$ ratio on the crystallization of $\mathrm{ZK}-5$.

\begin{tabular}{|c|c|c|c|c|}
\hline $\begin{array}{l}\text { Run } \\
\text { No }\end{array}$ & $\begin{array}{c}\mathrm{Al}_{2} \mathrm{O}_{3} \\
(y)\end{array}$ & $\begin{array}{c}\text { Si/Al } \\
\text { product }\end{array}$ & $\begin{array}{c}\text { Average Crystal } \\
\text { Size ZK5(nm) }\end{array}$ & $\%$ Crystallinity \\
\hline 1 & 1 & 2.7 & 87 & 86 \\
\hline 8 & 0.9 & 2.7 & 60 & 56 \\
\hline 9 & 0.8 & 2.8 & 52 & 43 \\
\hline 10 & 0.7 & 3.6 & - & - \\
\hline
\end{tabular}

Conventional hydrothermal synthesis. Time $144 \mathrm{~h}, \mathrm{Temp}=150^{\circ} \mathrm{C}$.

Batch Composition 2.3K $2 \mathrm{O}: 0.1 \mathrm{SrO}: \mathrm{yAl}_{2} \mathrm{O}_{3}: 10 \mathrm{SiO}_{2}: 160 \mathrm{H}_{2} \mathrm{O}: \mathrm{xTHF}, \mathrm{x}=0$.

-Amorphous 
Table 3

Influence of different $\mathrm{Si} / \mathrm{Al}$ ratio on the crystallization of $\mathrm{ZK}-5$ with a constant $\mathrm{THF} / \mathrm{Al}_{2} \mathrm{O}_{3}$ ratio of 0.5

\begin{tabular}{|c|c|c|c|c|c|}
\hline \multirow{3}{*}{$\begin{array}{l}\text { Run } \\
\text { No }\end{array}$} & \multicolumn{2}{|c|}{ Gel composition } & \multirow{3}{*}{$\begin{array}{c}\text { Si/Al } \\
\text { product }\end{array}$} & \multirow{3}{*}{$\begin{array}{l}\text { Average Crystal } \\
\text { Size ZK-5 (nm) }\end{array}$} & \multirow[t]{3}{*}{$\%$ Crystallinity } \\
\hline & $\overline{\mathrm{Al}_{2} \mathrm{O}_{3}}$ & THF & & & \\
\hline & $(\mathbf{y})$ & $(\mathbf{x})$ & & & \\
\hline 4 & 1.0 & 0.5 & 2.7 & 66 & 100 \\
\hline 11 & 0.9 & 0.45 & 2.7 & 54 & 78 \\
\hline 12 & 0.8 & 0.40 & 2.9 & 41 & 40 \\
\hline 13 & 0.7 & 0.35 & 3.5 & - & - \\
\hline $\begin{array}{l}\text { Con } \\
2.3 \mathrm{~K} \\
-\mathrm{Am}\end{array}$ & $\begin{array}{l}\text { nal h } \\
\text { SrO } \\
\text { as }\end{array}$ & & sis & & \\
\hline
\end{tabular}




\section{Figure Captions}

Figure 1. XRD patterns of ZK-5 zeolites obtained by hydrothermal synthesis at $150^{\circ} \mathrm{C}$,

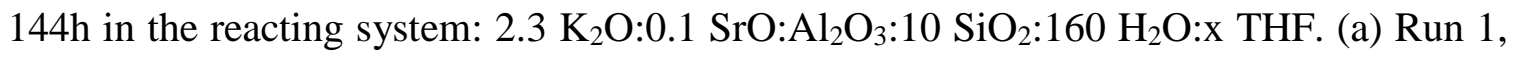
$x=0$, (b) Run 2, $x=0.2$, (c) Run 3, $x=0.4$, (d) Run 4, $x=0.5$, (e) Run 5, $x=1.0$, (f) Run 6, $x=$ 2.0, (g) Run 7, x=3.0

Figure 2. FESEM micrographs of ZK-5 zeolites obtained by hydrothermal synthesis at $150^{\circ} \mathrm{C}, 144 \mathrm{~h}$ in the reacting system: $2.3 \mathrm{~K}_{2} \mathrm{O}: 0.1 \mathrm{SrO}: \mathrm{Al}_{2} \mathrm{O}_{3}: 10 \mathrm{SiO}_{2}: 160 \mathrm{H}_{2} \mathrm{O}: \mathrm{x}$ THF. (a) Run 1, $x=0$, (b) Run 2, $x=0.2$, (c) Run 3, $x=0.4$, (d) Run 4, $x=0.5$, (e) Run 5, $x=1.0$, (f) Run 6, $\mathrm{x}=2.0,(\mathrm{~g}) \operatorname{Run} 7, \mathrm{x}=3.0$

Figure 3. XRD patterns of ZK-5 zeolites obtained by hydrothermal synthesis at $150^{\circ} \mathrm{C}$, 144h in the reacting system: $2.3 \mathrm{~K}_{2} \mathrm{O}: 0.1 \mathrm{SrO}: \mathrm{y}_{2} \mathrm{O}_{3}: 10 \mathrm{SiO}_{2}: 160 \mathrm{H}_{2} \mathrm{O}:$ x THF. Molar ratio $\mathrm{THF} / \mathrm{Al}_{2} \mathrm{O}_{3}=0$ for samples from (a) to (d) and $\mathrm{THF} / \mathrm{Al}_{2} \mathrm{O}_{3}=0.5$ for samples from (e) to (h). (a) Run 1, y=1.0, (b) Run 8, y=0.9 (c) Run 9, y=0.8 (d) Run 10, y=0.7, (e ) Run 4, $\mathrm{y}=1.0$ (f) Run 11, y=0.9 (g) Run 12, y=0.8 (h) Run 13, y=0.7.

Figure 4. FESEM micrographs of ZK-5 zeolites obtained by hydrothermal synthesis at $150^{\circ} \mathrm{C}, 144 \mathrm{~h}$ in the reacting system: $2.3 \mathrm{~K}_{2} \mathrm{O}: 0.1 \mathrm{SrO}: \mathrm{yAl}_{2} \mathrm{O}_{3}: 10 \mathrm{SiO}_{2}: 160 \mathrm{H}_{2} \mathrm{O}: \mathrm{x}$ THF. Molar ratio $\mathrm{THF} / \mathrm{Al}_{2} \mathrm{O}_{3}=0$ for samples from (a) to (d) and $\mathrm{THF} / \mathrm{Al}_{2} \mathrm{O}_{3}=0.5$ for samples from (e) to (h). (a) Run 1, y=1.0, (b) Run 8, y=0.9 (c) Run 9, y=0.8 (d) Run 10, y=0.7, (e ) Run 4, y=1.0 (f) Run 11, y=0.9 (g) Run 12, y=0.8 (h) Run 13, y=0.7.

Figure 5. TGA result of ZK-5 zeolite obtained by hydrothermal synthesis at $150^{\circ} \mathrm{C}, 144 \mathrm{~h}$

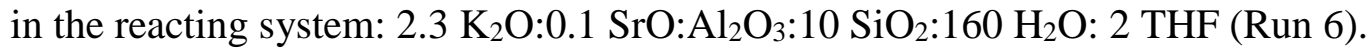


Figure 6. TPD-MS results for ZK-5 sample (Run 6 Table 1) obtained by hydrothermal treatment at $150^{\circ} \mathrm{C}, 144 \mathrm{~h}$ in the reacting system: $2.3 \quad \mathrm{~K}_{2} \mathrm{O}: 0.1 \mathrm{SrO}: \mathrm{Al}_{2} \mathrm{O}_{3}: 10 \quad \mathrm{SiO}_{2}: 160$ $\mathrm{H}_{2} \mathrm{O}: 2$ THF. 


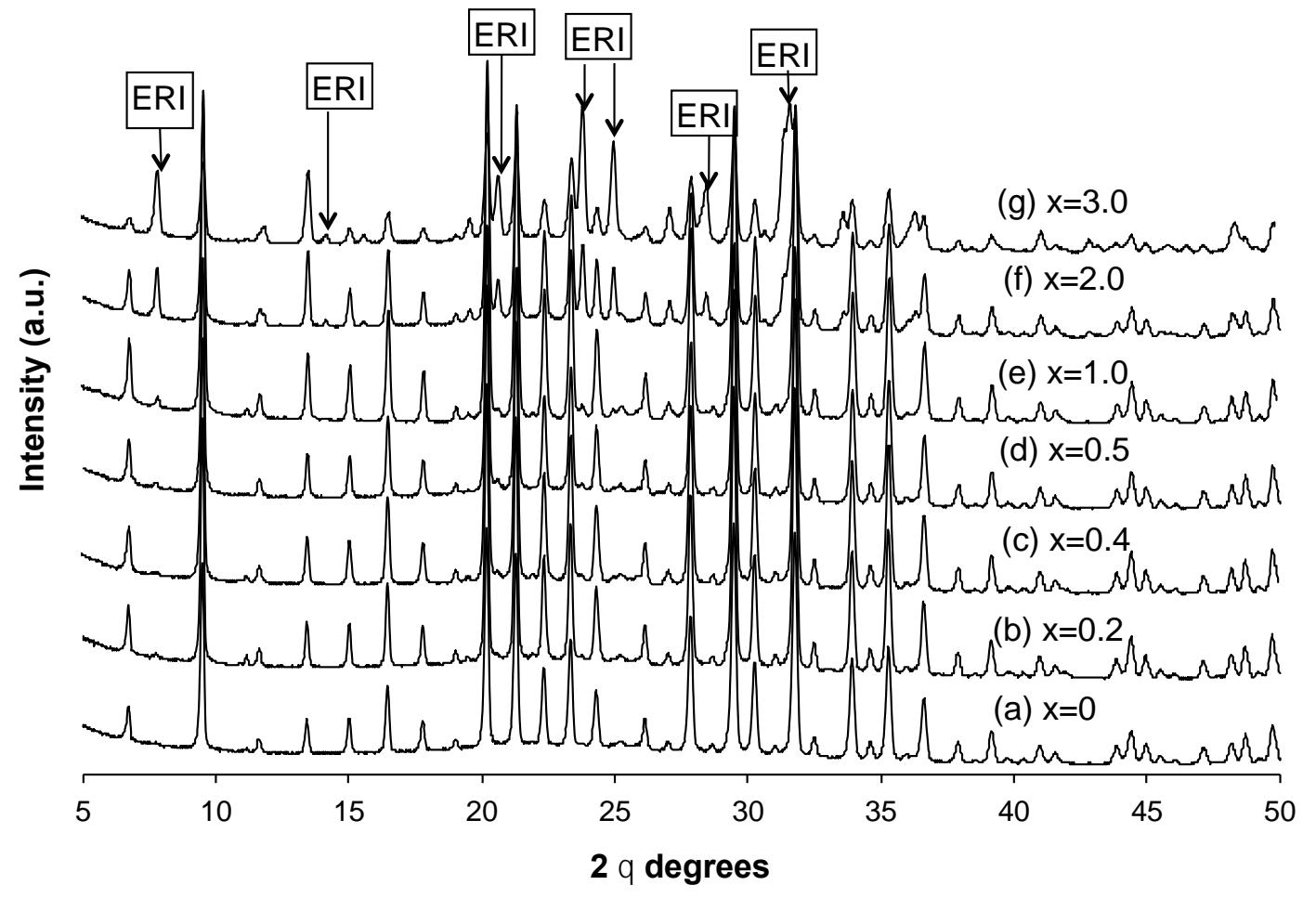

Figure 1. 

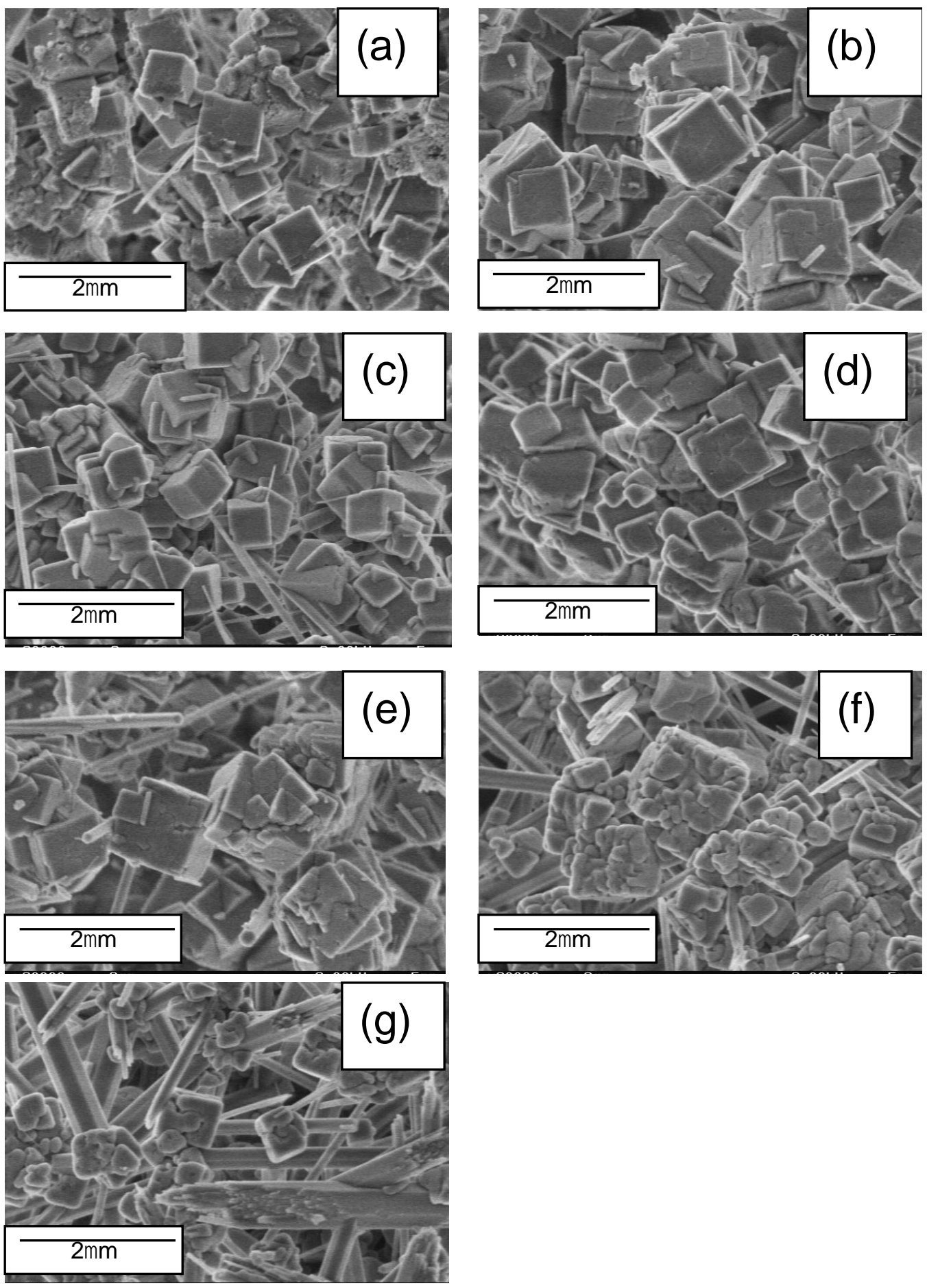

Figure 2. 


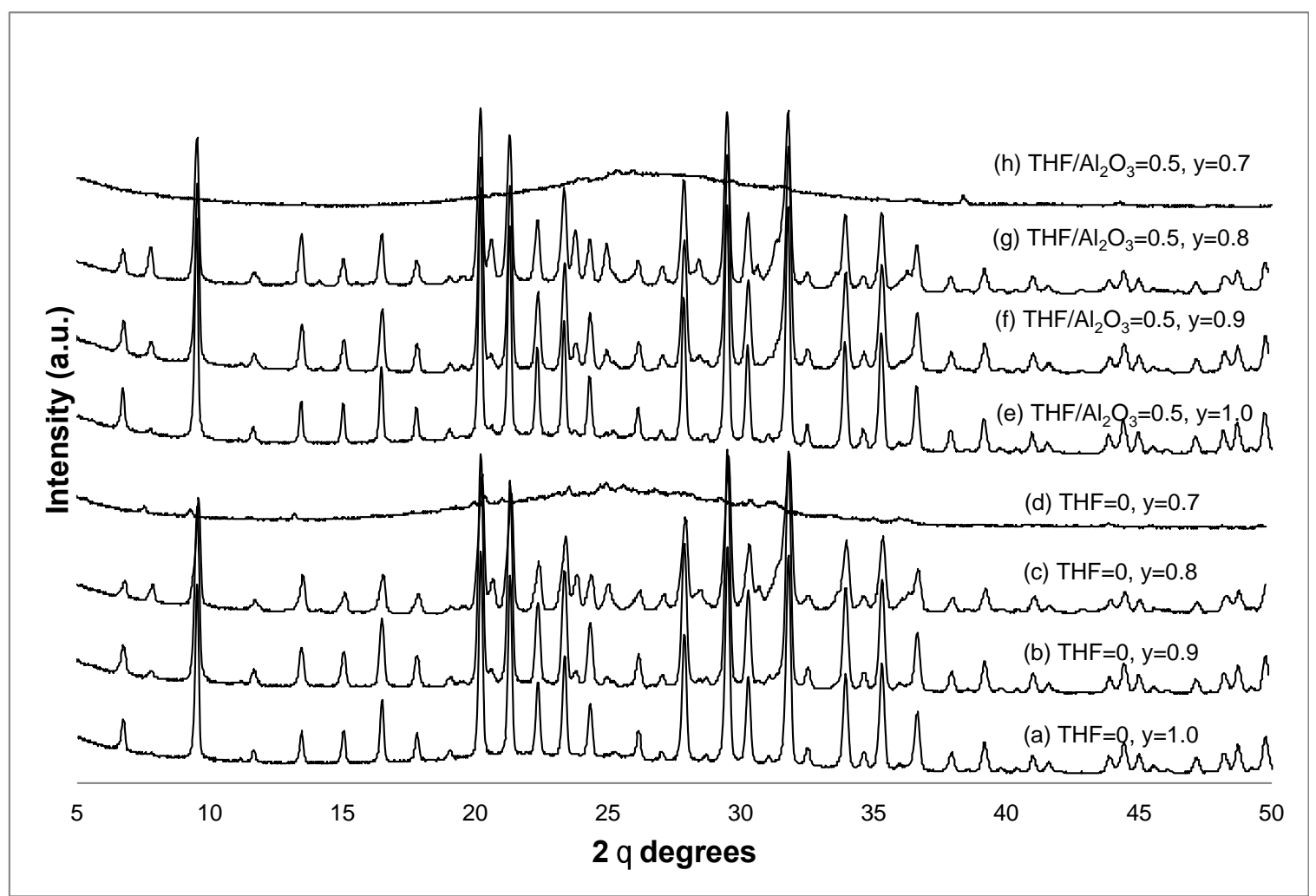

Figure 3 

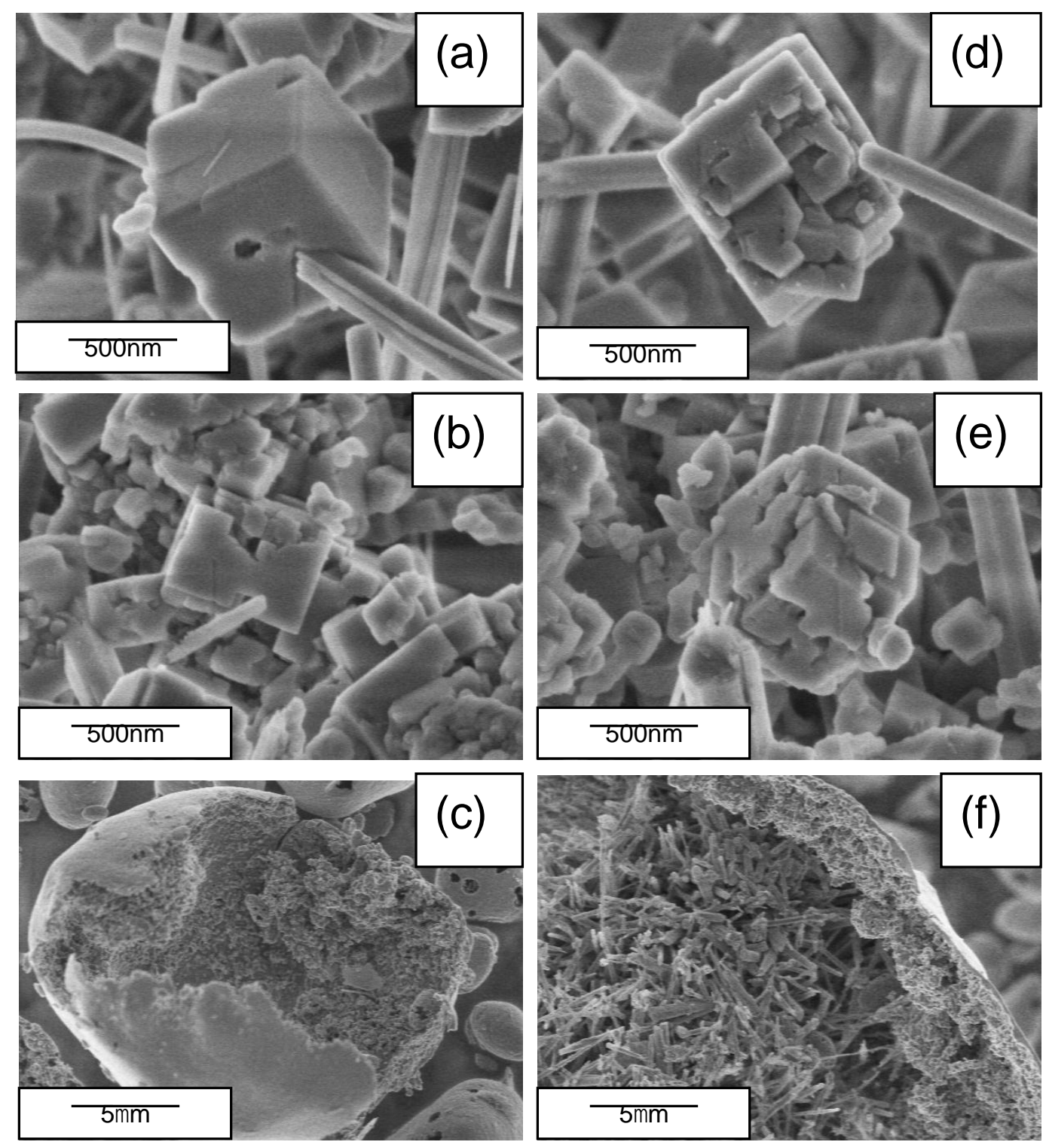

Figure 4 


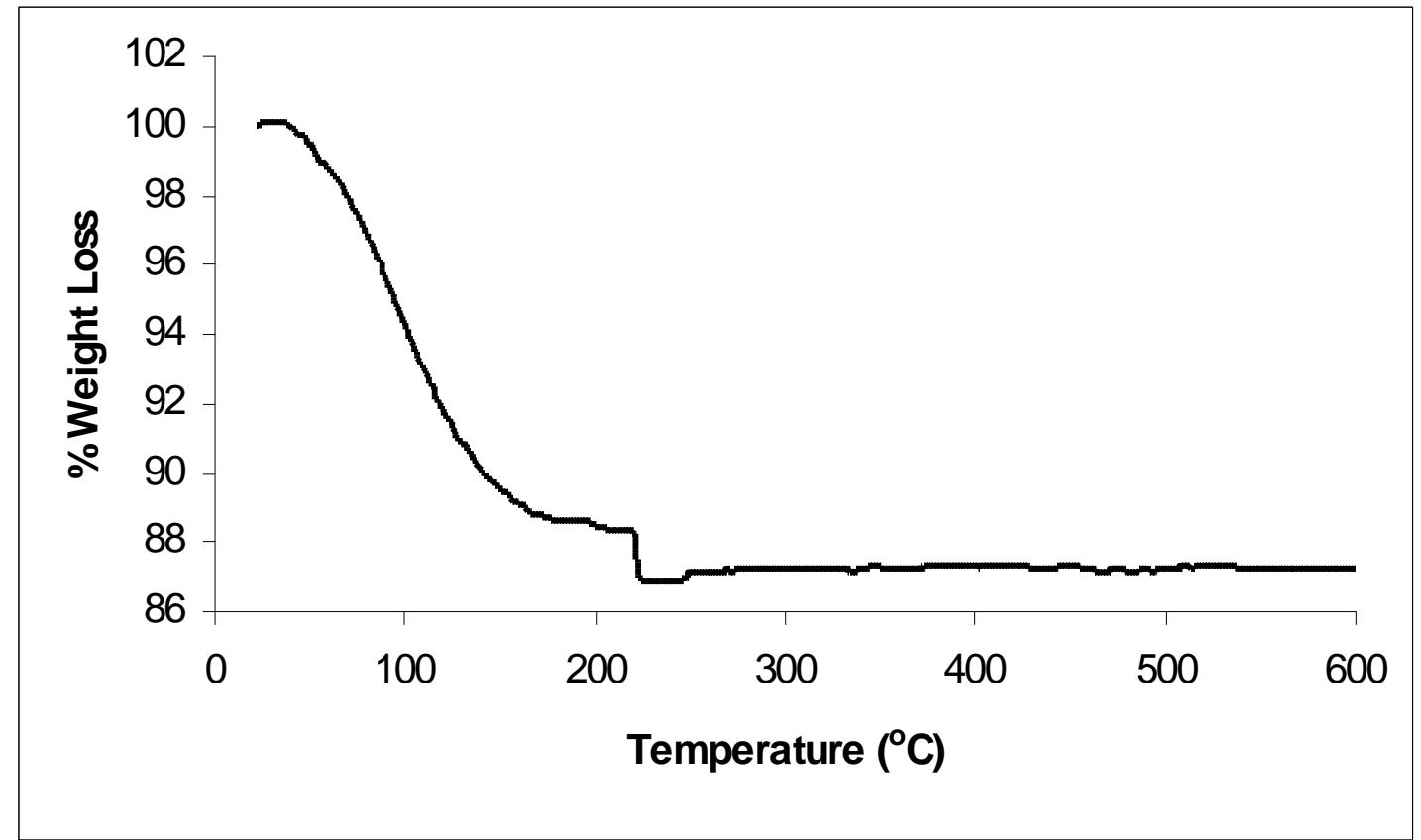

Figure 5 


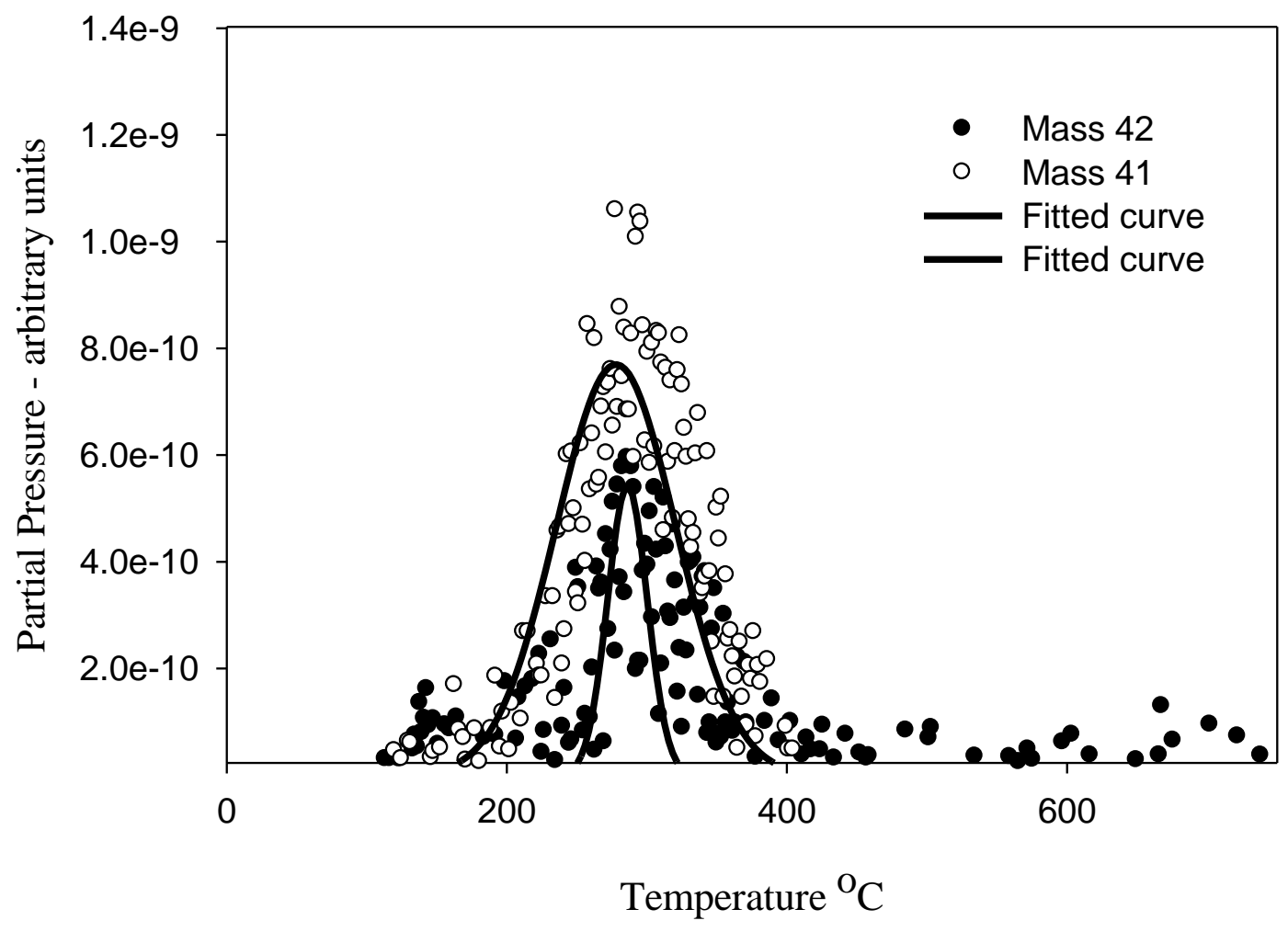

Figure 6 
ZK-5 